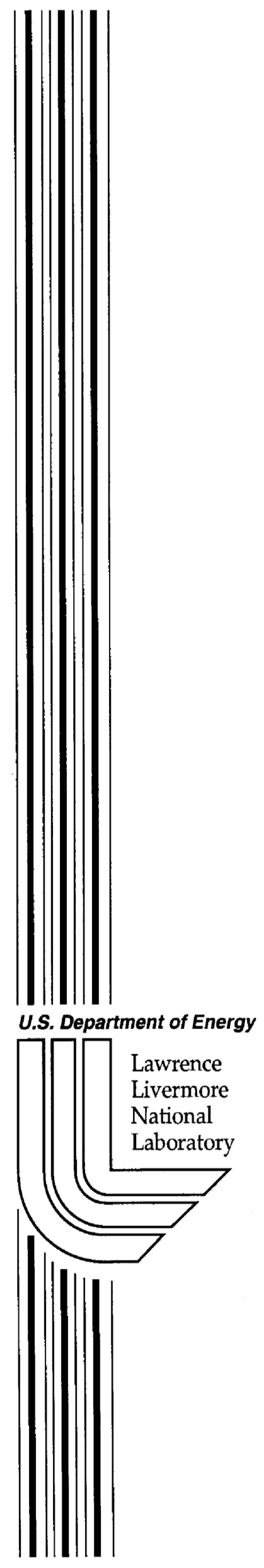

UCRL-ID-139780

\title{
Testing of the IMRA Wattlite Laser
}

\author{
B. Subrat, G. Erbert
}

June 21, 2000 


\section{DISCLAIMER}

This document was prepared as an account of work sponsored by an agency of the United States Government. Neither the United States Government nor the University of California nor any of their employees, makes any warranty, express or implied, or assumes any legal liability or responsibility for the accuracy, completeness, or usefulness of any information, apparatus, product, or process disclosed, or represents that its use would not infringe privately owned rights. Reference herein to any specific commercial product, process, or service by trade name, trademark, manufacturer, or otherwise, does not necessarily constitute or imply its endorsement, recommendation, or favoring by the United States Government or the University of California. The views and opinions of authors expressed herein do not necessarily state or reflect those of the United States Government or the University of California, and shall not be used for advertising or product endorsement purposes.

This work was performed under the auspices of the U. S. Department of Energy by the University of California, Lawrence Livermore National Laboratory under Contract No. W-7405-Eng-48.

This report has been reproduced directly from the best available copy.

Available electronically at http://www.doc.gov/bridge

Available for a processing fee to U.S. Department of Energy

And its contractors in paper from

U.S. Department of Energy

Office of Scientific and Technical Information

P.O. Box 62

Oak Ridge, TN 37831-0062

Telephone: (865) 576-8401

Facsimile: (865) 576-5728

E-mail: reports@adonis.osti.gov

Available for the sale to the public from

U.S. Department of Commerce

National Technical Information Service

5285 Port Royal Road

Springfield, VA 22161

Telephone: (800) 553-6847

Facsimile: (703) 605-6900

E-mail: orders@ntis.fedworld.gov

Online ordering: http://www.ntis.gov/ordering.htm

OR

Lawrence Livermore National Laboratory

Technical Information Department's Digital Library

http:/ / www.llnl.gov/tid/Library.html 


\section{Testing of the IMRA Wattlite laser}

Long term testing of the IMRA Wattlite oscillator began this month. The oscillator was operated for over 250 hours while monitoring the output power, the center wavelength and the pointing stability. Due to safety requirements, data was only collected during normal working hours. At night, the external (LLNL) shutter was closed so no data was collected, however, the laser continued to operate. In this mode of operation, approximately 80 hours of data was taken during the 250 hours of operation. The laser was turned off during the two weekend periods of this test series and restarted the following Monday. The warm-up period of the oscillator is most evident in the wavelength data shown in Figure 1. During the two cold start periods, the laser required about two hours for the wavelength to stabilize. Excluding the warm-up periods, the wavelength drift was approximately $\pm 0.1 \mathrm{~nm}$ over the 250 hours of operation.

The output power was monitored with a large area photo-diode. A plot of the output power as a function of time is shown in Figure 2. The two cold start periods are also evident in this data showing the same two-hour warm-up period for the power to stabilize. Once the laser was stable, the output power varied by only a few percent. It is also important to note that there is no degradation in the output power over the 250 hours of operation.

The pointing error from the oscillator was monitored by focusing the output beam onto a video camera. The data acquisition program finds the centroid of the focused spot to the nearest pixel on the CCD array. The resolution of the system was 42 micro-radians/pixel in the horizontal axis and 49 microradians/pixel in the vertical axis. A plot of the pointing error as a function of time is shown in Figures 3 and 4 . The pointing errors recorded are very small and are near the resolution of the diagnostic system. This is not surprising considering the output beam is from a single mode fiber. The pointing stability should only be related to how rigidly the output end of the fiber is mounted. Another advantage of the fiber output is that the pointing does not change as the laser warms up from a cold start.

Although a warm-up period is required for the IMRA oscillator, the long term stability in power, wavelength and pointing appear to be sufficient for the prototype laser system. 


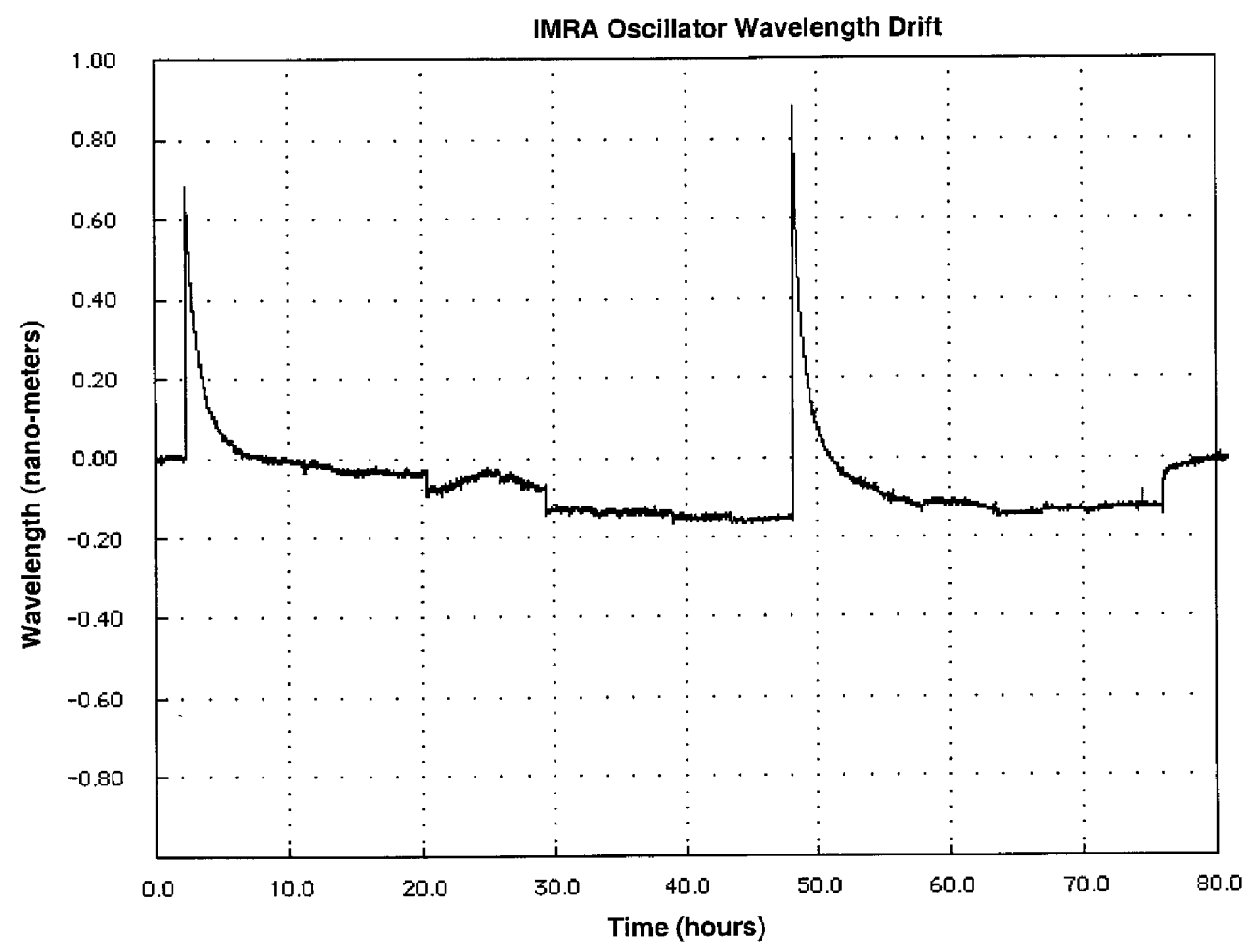

Figure 1. Wavelength drift in the IMRA oscillator as a function of time. The two large spikes are caused by the oscillator warming up from a cold start.

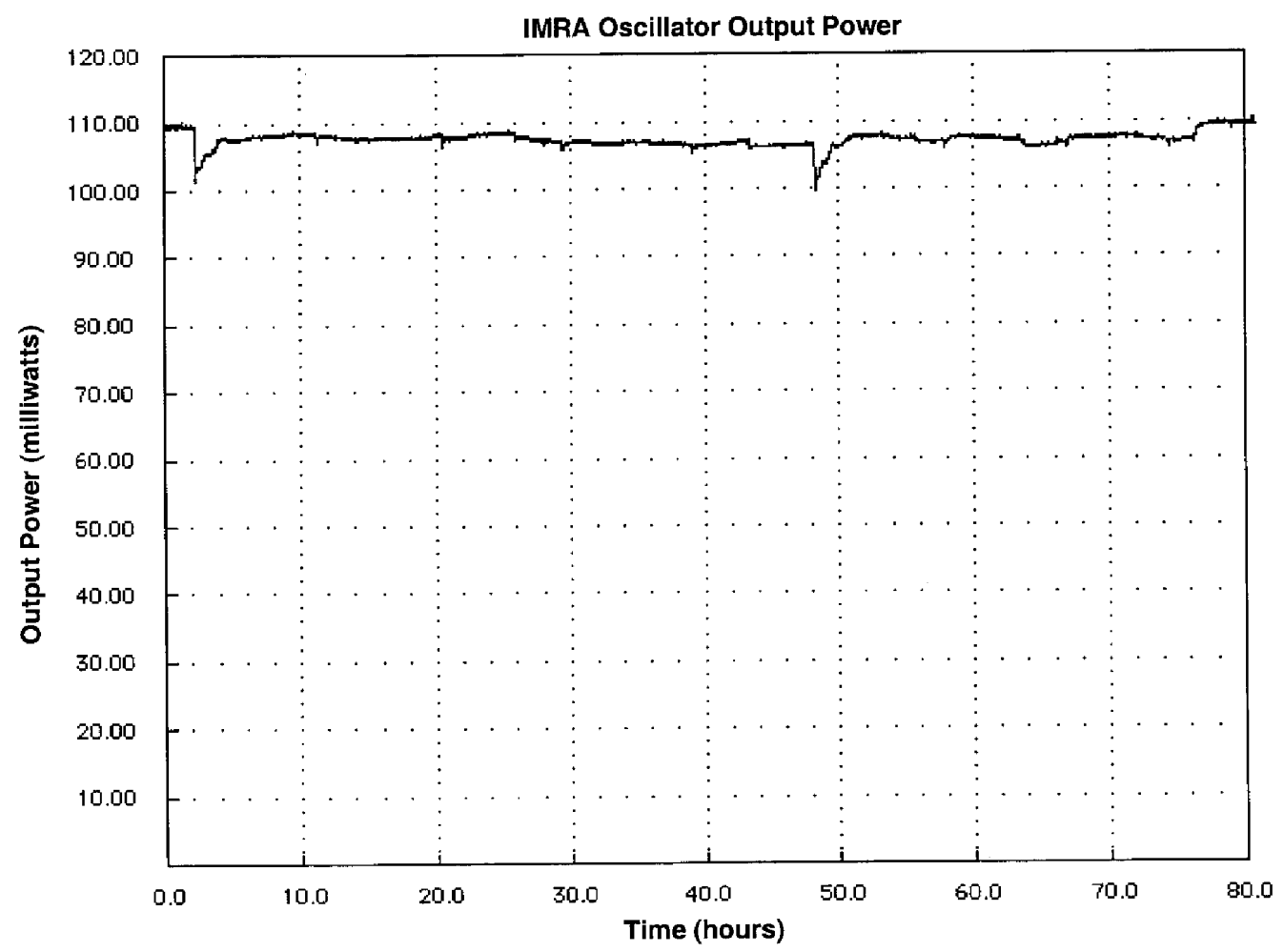

Figure 2. Output power of the IMRA oscillator as a function of time. 


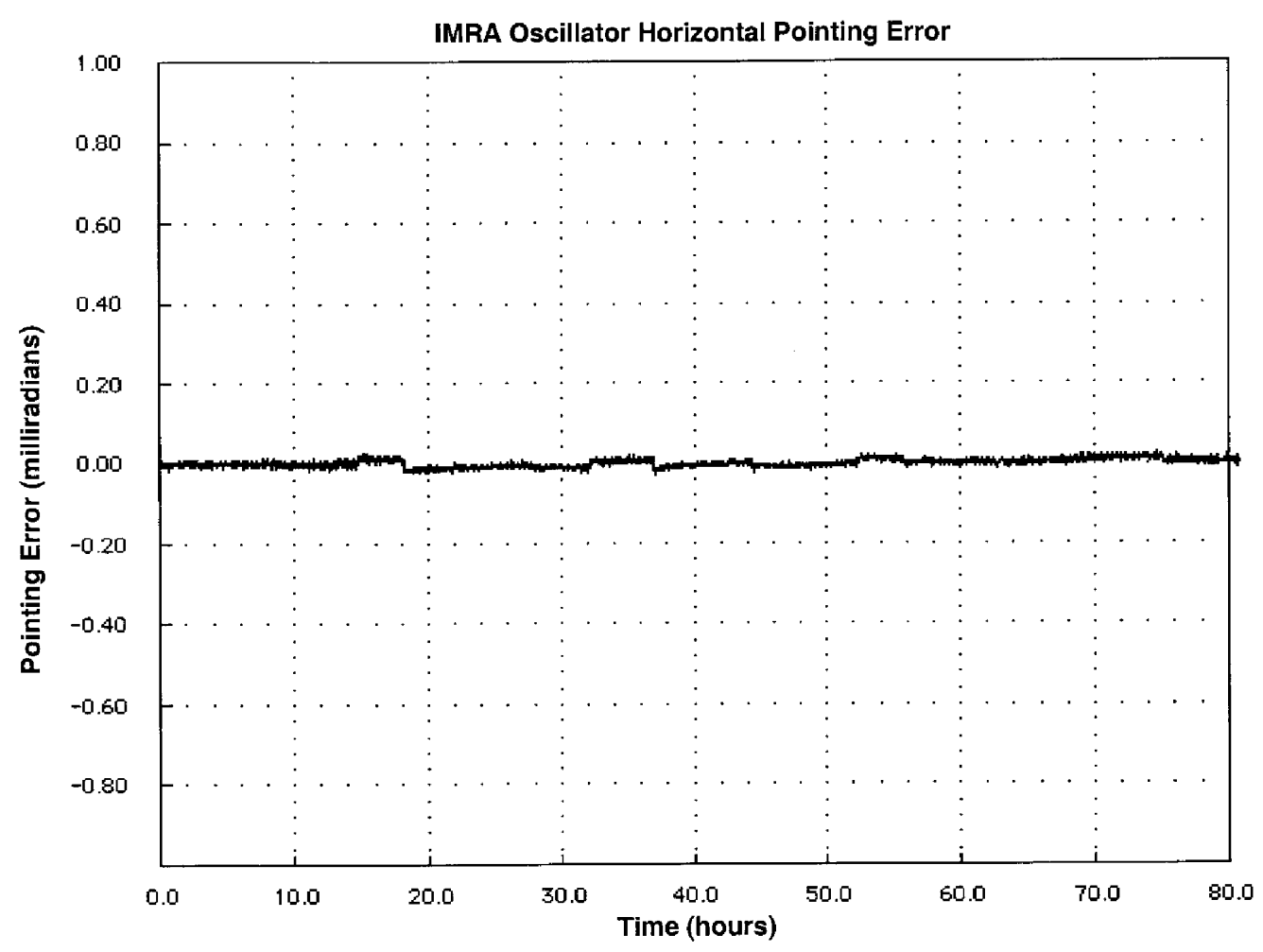

Figure 3. IMRA oscillator horizontal pointing error as a function of time.

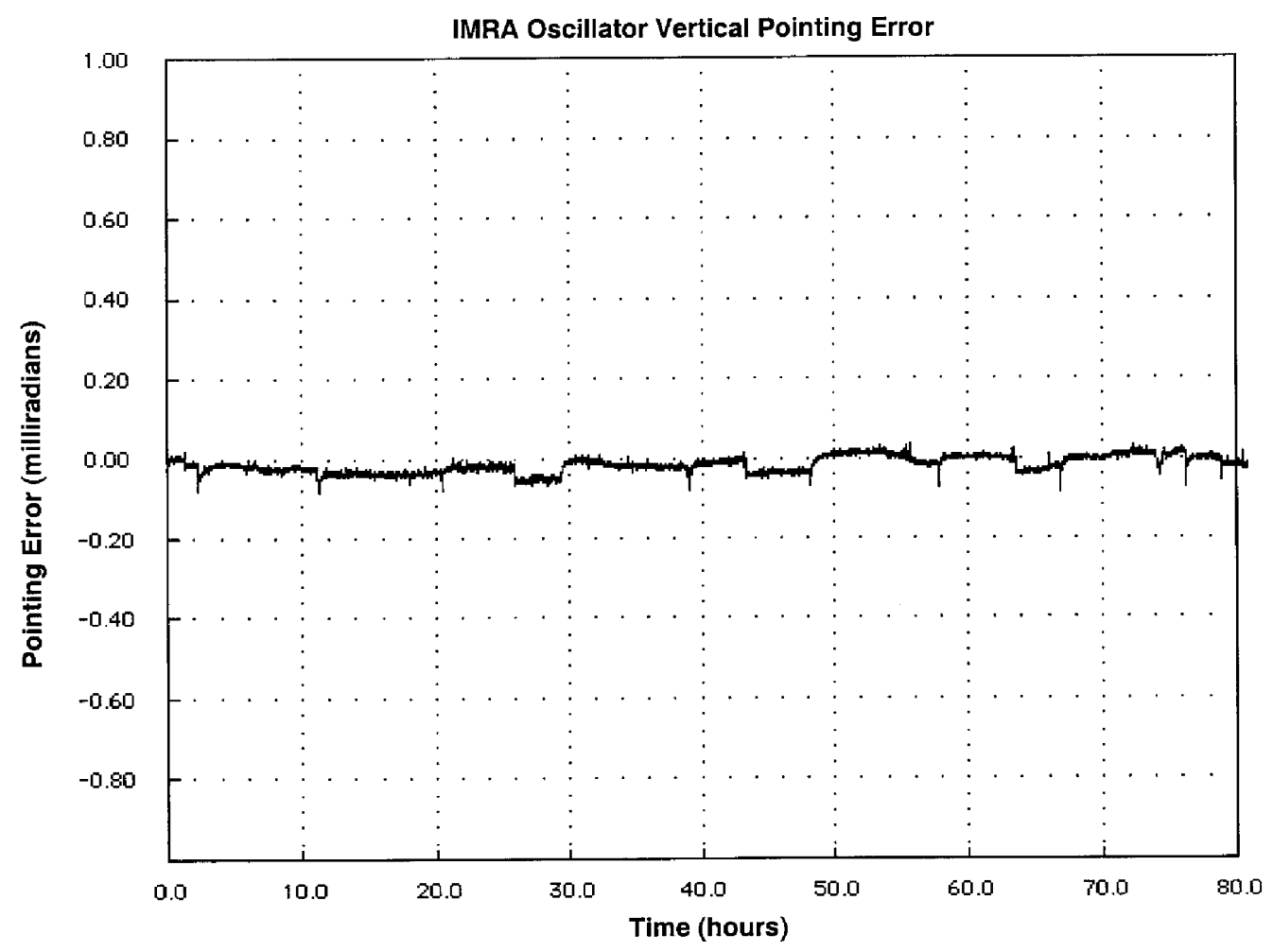

Figure 4. IMRA oscillator vertical pointing error as a function of time. 


\section{IMRA oscillator pulse compressibility}

The final remaining issue with the IMRA oscillator is the compressibility of the output pulses. The phase of the pulse, $\phi(\omega)$ can be represented by a Taylor expansion about the central frequency, $\omega_{0}$ :

$$
\phi(\omega)=\phi_{0}+\phi_{1}\left(\omega-\omega_{0}\right)+\phi_{2}\left(\omega-\omega_{0}\right)^{2}+\phi_{3}\left(\omega-\omega_{0}\right)^{3}+\phi_{4}\left(\omega-\omega_{0}\right)^{4}+\ldots
$$

In order for the amplified pulse to be transform limited (meaning the shortest pulsewidth for the given bandwidth), the frequency dependent phase of the pulse must be zero or negligible. This simply means the higher order terms, $\phi_{\mathrm{n}}$ (for $n \geq 2$ ), must be negligible. As expected, the pulses from the IMRA oscillator does contain higher order phase terms, and thus not transform limited. Depending on the magnitude and sign, the higher order phase terms can be corrected for by using the stretcher/compressor. Therefore, the remaining task is to compress the pulses from the IMRA oscillator to transform limit. The pulses directly from the IMRA oscillator were measured to be 8 ps (Figure 5). The measurements done by ALD agreed with measurements performed at IMRA. Based on the measured output spectrum, the transform-limited pulses should be 425 fs FWHM.

Using a compressor (1200 lines/mm gratings) provided by IMRA, the pulses were compressed to 1.3 times transform limit. By clipping the bandwidth down to 2-nm FWHM in the compressor, pulses 1.1 times transform limit were obtained. These results were also comparable to those measured at IMRA.

Currently available optics were used to construct a stretcher and compressor similar to the actual design (larger optics will be used in the actual design). The output bandwidth from the compressor was limited to $0.8 \mathrm{~nm}$ FWHM due to the size of the available optics. Based on this spectrum the transform-limited pulses should be $2.7 \mathrm{ps}$ FWHM. The shortest pulses that we were able to obtain after stretching and compressing was a factor of 1.1 greater than the transform limit (see Figure 6). 


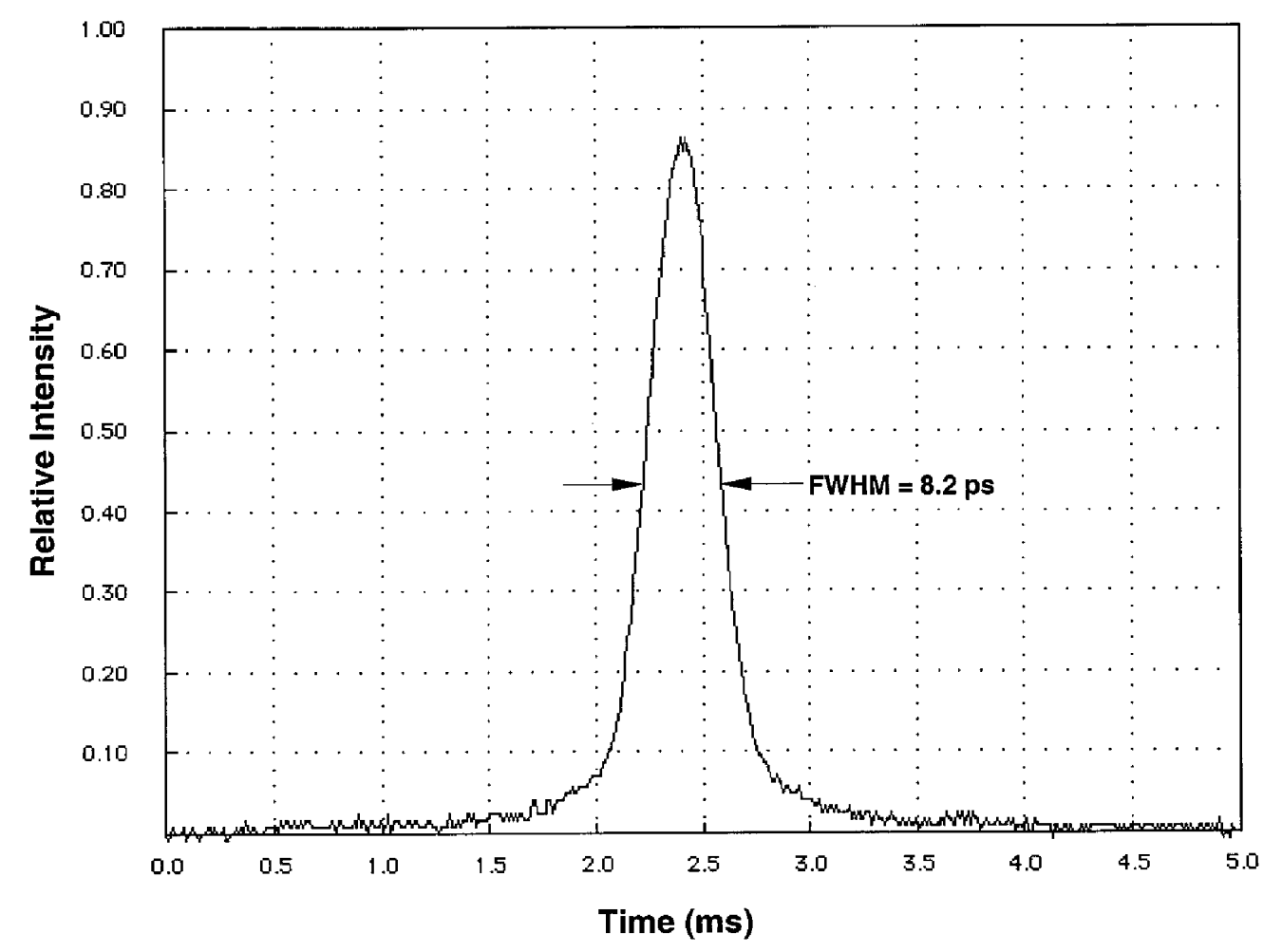

Figure 5. Auto-correlation trace showing output pulsewidth of IMRA oscillator. $8.2 \mathrm{ps}$ is the pulse intensity FWHM assuming a gaussian pulse. 


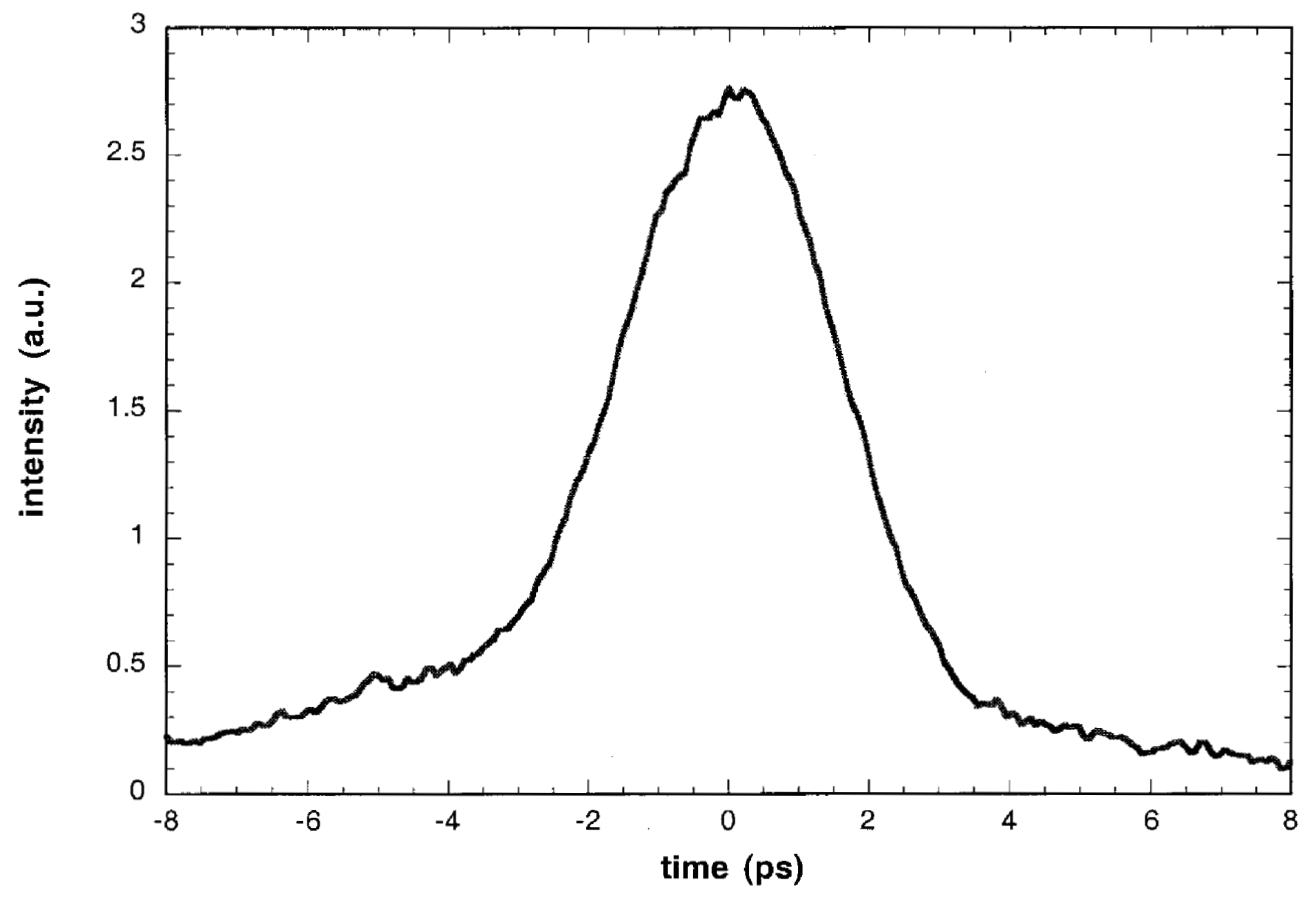

Figure 6. Auto-correlation (3.9 ps FWHM) after stretching and compressing. Corresponds to a 3-ps FWHM for the pulse intensity (factor 1.3 was calculated using measured spectrum, $0.8 \mathrm{~nm}$ FWHM). 